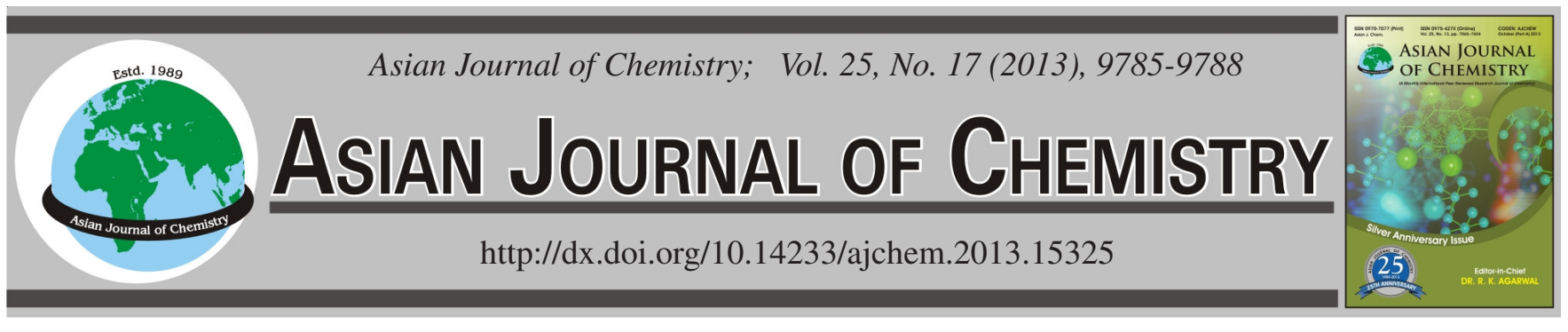

\title{
Determination of Surface Tension of Nanoscale Liquid Threads
}

Hong YAN" and XIAOFANG ZHOU

Department of Electronic Information and Physics, Changzhi University, Changzhi 046011, P.R. China

*Corresponding author: Tel: +86 15835586089; E-mail: yanh2010sx@yahoo.com.cn

(Received: 13 February 2013;

Accepted: 23 October 2013)

AJC-14275

For the determination of surface tension of liquid threads by molecular dynamics simulations, the most time-consuming part is the calculation of pressure tensor in the transition layer, which makes it difficult to enhance the precision of the computation. A new method for the calculation of surface tension of liquid threads to decrease the calculation quantity of pressure tensor in transition layer to the least is proposed in this paper. Four thousand eight hundred particles are taken to show how to carry out our scheme.

Key Words: Liquid thread, Surface tension, Equimolar Surface, Molecular dynamics simulation.

\section{INTRODUCTION}

Study of the surface properties is fueled by the development of nanotechnology. Surface tension is a characteristic property of fluids. In this paper we give a method for the surface tension determination of nanoscale liquid threads. The research on liquid threads has attracted people's attention for many years. It is important for many areas of applied science and technology, such as chemical engineering, coating, adsorption, adhesion and environmental protection ${ }^{1-3}$.

There are many studies on surface tension. Early studies were based on mechanics models and thermodynamic arguments. The statistical mechanics provides the more powerful methods. These methods usually employ the pressure tensor from statistical mechanics to evaluate the surface tension. The pressure tensor is not uniquely defined by the microscopic laws embodying the conservation of momentum and angular momentum. The variety of pressure tensor definition brings forward the nonuniqueness of surface tension and some other physical quantity for curved interface ${ }^{4,5}$. It is meaningful if we give a method that can determine the surface tension without use of pressure tensor.

On the basis of Gibbs theory ${ }^{6}$, we give a method that can determine the surface tension of nanoscale liquid threads without use of pressure tensors. In this paper nanoscale liquid threads are the subject of investigation. A derivation of the surface tension calculation is given. Then we carry out molecular dynamics simulations to adopt the scheme.

\section{EXPERIMENTAL}

Theoretical basis and calculation scheme: Consider the equimolar surface, there is and

$$
\mathrm{n}_{\mathrm{e}}=0
$$

$$
\mathrm{F}_{\mathrm{e}}=\mathrm{U}_{\mathrm{e}}-\mathrm{TS}_{\mathrm{e}}=\gamma_{\mathrm{e}} \mathrm{A}_{\mathrm{e}}
$$

where the subscript e indicate the equimolar surface and $n_{e}$ is the number of molecules per unit area of the equimolar surface, $\mathrm{U}_{\mathrm{e}}, \mathrm{F}_{\mathrm{e}}, \mathrm{S}_{\mathrm{e}} \gamma_{\mathrm{e}}$ and $\mathrm{A}_{\mathrm{e}}$ denote the surface energy, surface free energy, surface entropy, surface tension and the area of the equimolar surface, $\mathrm{T}$ is the temperature of the system.

Eqn. 2 gives

$$
\mathrm{dF}_{\mathrm{e}}=\gamma_{\mathrm{e}} \mathrm{dA} \mathrm{A}_{\mathrm{e}}+\mathrm{A}_{\mathrm{e}} \mathrm{d} \gamma_{\mathrm{e}}
$$

Considering the work of curvature change, we have ${ }^{6}$

$$
\mathrm{dF}_{\mathrm{e}}=-\mathrm{S}_{\mathrm{e}} \mathrm{dT}+\gamma_{\mathrm{e}} \mathrm{dA}_{\mathrm{e}}+\mathrm{A}_{\mathrm{e}}\left[\frac{\mathrm{d} \gamma}{\mathrm{dR}}\right]_{\mathrm{e}} \mathrm{dR}_{\mathrm{e}}
$$

where $\mathrm{R}$ denotes the radius of dividing surface, the differential in square bracket denotes change in function that follows from a notional change in the position of the dividing surface and $\mathrm{R}_{\mathrm{e}}$ denotes the radius of the equimolar surface and is determined by the equation

$$
\mathrm{N}=\rho_{1} \pi \mathrm{R}_{\mathrm{e}}^{2} \mathrm{~L}+\rho_{v}\left(\mathrm{~V}-\pi \mathrm{R}_{\mathrm{e}}^{2} \mathrm{~L}\right)
$$

where $\mathrm{N}, \mathrm{V}, \rho_{l}, \rho_{v}$ and $\mathrm{L}$ are the total number of molecules, total volume of the system, density of the interior of the liquid and that of the interior of the vapour, the length of the liquid thread, respectively.

Substituting eqn. 3 into 4 we obtain

$$
\mathrm{d} \gamma_{\mathrm{e}}\left(\mathrm{T}, \mathrm{R}_{\mathrm{e}}\right)=\frac{-\mathrm{S}_{\mathrm{e}}\left(\mathrm{T}, \mathrm{R}_{\mathrm{e}}\right)}{\mathrm{A}_{\mathrm{e}}} \mathrm{dT}+\left[\frac{\mathrm{d} \gamma(\mathrm{T}, \mathrm{R})}{\mathrm{dR}}\right] \mathrm{dR} \mathrm{R}_{\mathrm{e}}
$$

where $\gamma_{e}\left(T, R_{e}\right)$ can also be expressed by $\gamma\left(T, R_{e}\right)$. Eqn. 6 indicates that the differential of surface tension $d \gamma_{e}\left(T, R_{e}\right)$ depends 
on the two variables $\left(T, R_{e}\right)$ and their differentials $\left(d T, d R_{e}\right)$. The differential expressed by eqn. 6 is a total differential. The integral

$\int_{\left(\mathrm{T}_{0}, \mathrm{R}_{\mathrm{e} 0}\right)}^{\left(\mathrm{T}_{1}, \mathrm{R}_{\mathrm{e}}\right)} \mathrm{d} \gamma_{\mathrm{e}}\left(\mathrm{T}, \mathrm{R}_{\mathrm{e}}\right)=\int_{\left(\mathrm{T}_{0}, \mathrm{R}_{\mathrm{e} 0}\right)}^{\left(\mathrm{T}_{1}, \mathrm{R}_{\mathrm{e} 1}\right)}\left\{\frac{-\mathrm{S}_{\mathrm{e}}\left(\mathrm{T}, \mathrm{R}_{\mathrm{e}}\right)}{\mathrm{A}_{\mathrm{e}}} \mathrm{dT}+\left[\frac{\mathrm{d} \gamma(\mathrm{T}, \mathrm{R})}{\mathrm{dR}}\right]_{\mathrm{e}} \mathrm{dR} \mathrm{R}_{\mathrm{e}}\right\}$

must be determined by the origin point and end point and be independent of the path.

There are two different paths, i.e. restrictive conditions in the $\mathrm{TR}_{\mathrm{e}}$ plane

$$
\begin{gathered}
\mathrm{R}_{\mathrm{e}}=\mathrm{R}_{\mathrm{e}}(\mathrm{T}) \\
\mathrm{T}=\mathrm{T}_{0}
\end{gathered}
$$

and

$$
\text { e appointed arbitrarily. }
$$

where $\mathrm{R}_{\mathrm{e}}(\mathrm{T})$ and $\mathrm{T}_{0}$ may be appointed arbitrarily.

In this paper we discuss the surface tension determination under the restrictive conditions $R_{e}=R_{e}(T)$. Then the surface tension $\gamma_{\mathrm{e}}$ and entropy $\mathrm{S}_{\mathrm{e}}$ depend only on one variable $\mathrm{T}$ and can be expressed as $\gamma_{\mathrm{e}}(\mathrm{T})=\gamma_{\mathrm{e}}\left(\mathrm{T}, \mathrm{R}_{\mathrm{e}}(\mathrm{T})\right)=\gamma\left(\mathrm{T}, \mathrm{R}_{\mathrm{e}}(\mathrm{T})\right.$ and $\mathrm{S}_{\mathrm{e}}(\mathrm{T})=\mathrm{S}_{\mathrm{e}}\left(\mathrm{T}, \mathrm{R}_{\mathrm{e}}(\mathrm{T})\right)$. Eqn. 6 becomes the monadic differential form

$$
\begin{array}{r}
d \gamma_{e}\left(T, R_{e}(T)\right)=\frac{-S_{e}\left(T, R_{e}(T)\right)}{A_{e}} d T+\left[\frac{d(T, R))}{d R}\right]_{e} \\
\left(\frac{d_{e}(T)}{d T}\right) d T
\end{array}
$$

which gives

$$
\frac{\mathrm{d} \gamma_{\mathrm{e}}\left(\mathrm{T}, \mathrm{R}_{\mathrm{e}}(\mathrm{T})\right)}{\mathrm{dT}}=\frac{-\mathrm{S}_{\mathrm{e}}\left(\mathrm{T}, \mathrm{R}_{\mathrm{e}}(\mathrm{T})\right)}{\mathrm{A}_{\mathrm{e}}}+\left[\frac{\mathrm{d} \gamma(\mathrm{T}, \mathrm{R})}{\mathrm{dR}}\right]_{\mathrm{e}}\left(\frac{\mathrm{dR} \mathrm{e}(\mathrm{T})}{\mathrm{dT}}\right)(10)
$$

From eqns. 2 and 10, we have

$$
\begin{gathered}
\frac{\mathrm{d} \gamma_{\mathrm{e}}\left(\mathrm{T}, \mathrm{R}_{\mathrm{e}}(\mathrm{T})\right)}{\mathrm{dT}}=\frac{\gamma_{\mathrm{e}}\left(\mathrm{T}, \mathrm{R}_{\mathrm{e}}(\mathrm{T})\right)}{\mathrm{T}}-\frac{\varepsilon_{\mathrm{e}}\left(\mathrm{T}, \mathrm{R}_{\mathrm{e}}(\mathrm{T})\right)}{\mathrm{T}} \\
+\left[\frac{\mathrm{d} \gamma(\mathrm{T}, \mathrm{R})}{\mathrm{dR}}\right]_{\mathrm{e}} \frac{\mathrm{dR} \mathrm{R}_{\mathrm{e}}(\mathrm{T})}{\mathrm{dT}}
\end{gathered}
$$

where $\varepsilon_{\mathrm{e}}$ is the energy per unit area of the equimolar surface. Eqn. 10 with the general Laplace equation ${ }^{7}$

$$
\begin{gathered}
\Delta \mathrm{p}=\mathrm{p}_{1}-\mathrm{p}_{\mathrm{v}}=\frac{\gamma_{\mathrm{e}}}{\mathrm{R}_{\mathrm{e}}}+\left[\frac{\mathrm{d} \gamma}{\mathrm{dR}}\right]_{\mathrm{e}} \\
\text { gives } \frac{\mathrm{d} \gamma_{\mathrm{e}}\left(\mathrm{T}, \mathrm{R}_{\mathrm{e}}(\mathrm{T})\right)}{\mathrm{dT}}+\left(\mathrm{T} \frac{\mathrm{dR} \mathrm{e}_{\mathrm{e}}(\mathrm{T})}{\mathrm{dT}} \frac{1}{\mathrm{R}_{\mathrm{e}}}-1\right) \frac{\gamma_{\mathrm{e}}\left(\mathrm{T}, \mathrm{R}_{\mathrm{e}}(\mathrm{T})\right)}{\mathrm{T}} \\
=\Delta \mathrm{p}\left(\mathrm{T}, \mathrm{R}_{\mathrm{e}}(\mathrm{T})\right) \frac{\mathrm{dR}_{\mathrm{e}}(\mathrm{T})}{\mathrm{dT}}-\frac{\varepsilon_{\mathrm{e}}\left(\mathrm{T}, \mathrm{R}_{\mathrm{e}}(\mathrm{T})\right)}{\mathrm{T}}
\end{gathered}
$$

where $p_{1}$ and $p_{v}$ are the pressures in the interior of the liquid and in the interior of the vapour, respectively.

For a nanoscale liquid thread, if we have a function $R_{e}(T)$ arbitrarily and know the functions $\varepsilon_{\mathrm{e}}(\mathrm{T})=\varepsilon_{\mathrm{e}}\left(\mathrm{T}, \mathrm{R}_{\mathrm{e}}(\mathrm{T})\right)$ and $\Delta \mathrm{p}(\mathrm{T})=\Delta \mathrm{p}\left(\mathrm{T}, \mathrm{R}_{\mathrm{e}}(\mathrm{T})\right)$, then eqn. 13 is a first-order ordinary differential equation for function $\gamma_{e}(T)=\gamma_{e}\left(T, R_{e}(T)\right)$. The solution of eqn. 13 is

$$
\begin{aligned}
& \gamma_{\mathrm{e}}(\mathrm{T})=\gamma_{\mathrm{e}}\left(\mathrm{T}, \mathrm{R}_{\mathrm{e}}(\mathrm{T})\right) \\
& =\mathrm{e}^{-\int_{\mathrm{T}_{0}}^{\mathrm{T}}\left(\mathrm{T}^{\prime} \frac{\mathrm{dR}_{\mathrm{e}}}{\mathrm{dT}^{\prime}} \frac{1}{\mathrm{R}_{\mathrm{e}}}-1\right) \frac{\mathrm{dT}^{\prime}}{\mathrm{T}^{\prime}}}
\end{aligned}
$$

$$
\begin{aligned}
& \left(\int_{\mathrm{T}_{0}}^{\mathrm{T}}\left(\Delta \mathrm{p} \frac{\mathrm{dR}}{\mathrm{dT}_{\mathrm{e}}^{\prime}}-\frac{\varepsilon_{\mathrm{e}}}{\mathrm{T}^{\prime}}\right) \mathrm{e}^{\int_{\mathrm{T}_{0}}^{\mathrm{T}^{\prime}}\left(\mathrm{T}^{\prime \prime} \frac{\mathrm{dR}_{\mathrm{e}}}{\mathrm{dT}} \frac{1}{\mathrm{R}_{\mathrm{e}}}-1\right) \frac{\mathrm{dT}^{\prime \prime}}{\mathrm{T}^{\prime}}} \mathrm{dT}^{\prime}+\gamma_{\mathrm{e}}\left(\mathrm{T}_{0}, \mathrm{R}_{\mathrm{e}}\left(\mathrm{T}_{0}\right)\right)\right. \\
& =\frac{\mathrm{T}}{2 \mathrm{R}_{\mathrm{e}}(\mathrm{T})}\left(\mathrm{R}_{\mathrm{e}}^{2}\left(\mathrm{~T}^{\prime}\right) \frac{\Delta \mathrm{p}\left(\mathrm{T}^{\prime}\right)}{\mathrm{T}^{\prime}} \mid \mathrm{T} \mathrm{T}_{0}-\int_{\mathrm{T}_{0}}^{\mathrm{T}} \mathrm{R}_{\mathrm{e}}^{2}\left(\mathrm{~T}^{\prime}\right) \frac{\mathrm{T}^{\prime} \frac{\mathrm{d} \Delta \mathrm{p}}{\mathrm{d \textrm {T } ^ { \prime }}-\Delta \mathrm{r}\left(\mathrm{T}^{\prime}\right)}}{\mathrm{T}^{\prime 2}} \mathrm{dT}^{\prime}\right) \\
& -\frac{\mathrm{T}}{\mathrm{R}_{\mathrm{e}}(\mathrm{T})} \int_{\mathrm{T}_{0}}^{\mathrm{T}} \frac{\varepsilon_{\mathrm{e}}\left(\mathrm{T}^{\prime}\right) \mathrm{R}_{\mathrm{e}}\left(\mathrm{T}^{\prime}\right)}{\mathrm{T}^{\prime 2}} \mathrm{dT}^{\prime}+\gamma_{\mathrm{e}}\left(\mathrm{T}_{0}, \mathrm{R}_{\mathrm{e}}\left(\mathrm{T}_{0}\right)\right) \frac{\mathrm{TR}_{\mathrm{e}}\left(\mathrm{T}_{0}\right)}{\mathrm{T}_{0} \mathrm{R}_{\mathrm{e}}(\mathrm{T})}(14)
\end{aligned}
$$

Formula (14) permits us to calculate function $\gamma_{\mathrm{e}}(\mathrm{T})=\gamma_{\mathrm{e}}(\mathrm{T}$, $\left.\mathrm{R}_{\mathrm{e}}(\mathrm{T})\right)$ in any given interval $\left(\mathrm{T}_{0}, \mathrm{~T}_{1} ; \mathrm{T}_{0} \neq \mathrm{T}_{1}\right)$ for a given single component liquid and a given function $\mathrm{R}_{\mathrm{e}}(\mathrm{T})$ in interval $\left(\mathrm{T}_{0}\right.$, $\left.\mathrm{T}_{1}\right)$, if the value $\gamma_{\mathrm{e}}\left(\mathrm{T}_{0}\right)$ is known and functions $\Delta \mathrm{p}(\mathrm{t})$ and $\varepsilon_{\mathrm{e}}(\mathrm{T})$ in interval $\left(\mathrm{T}_{0}, \mathrm{~T}_{1}\right)$ are also known. In fact, the $\gamma_{\mathrm{e}}\left(\mathrm{T}_{0}\right)$ can be obtained through experimental measurement or by calculation with use of the molecular dynamics simulation results of pressure tensors in the transition layer. The function can be calculated by molecular dynamics simulation in the interiors of the liquid threads and the vapour and the function

$$
\varepsilon_{\mathrm{e}}(\mathrm{T})=\frac{1}{2 \pi \mathrm{R}_{\mathrm{e}} \mathrm{L}}\left(\mathrm{E}-\pi \mathrm{R}_{\mathrm{e}}^{2} \mathrm{~L} \varepsilon_{1}-\left(\mathrm{V}-\pi \mathrm{R}_{\mathrm{e}}^{2} \mathrm{~L}\right) \varepsilon_{\mathrm{v}}\right)
$$

can be calculated by molecular dynamics simulation with eqn. 5 , where $\mathrm{E}, \varepsilon_{1}$ and $\varepsilon_{\mathrm{v}}$ are the total energy, energy density of the interior of the liquid and that of the interior of the vapour, respectively. And so we need not use the pressure tensor in surface layer. Besides, to calculate $\mathrm{E}, \varepsilon_{1}$ and $\varepsilon_{\mathrm{v}}$ in eqn. 15 , we must use the energy of a molecule

$$
\mathrm{E}_{\mathrm{m}}=\frac{\mathrm{m}}{2} v^{2}+\frac{\mathrm{U}}{2}
$$

where $\mathrm{m}, \mathrm{v}$ and $\mathrm{U}$ are molecular mass, molecular speed and inter-molecule potential, respectively.

Now we show how to obtain an initial value $\gamma_{\mathrm{e} 0}=\gamma\left(\mathrm{T}_{0}\right.$, $\mathrm{R}_{\mathrm{e} 0)}$ by molecular dynamics simulation for lack of experiment data. For a surface of tension with radius $\mathrm{R}_{\mathrm{S}}$, we can use the expression as follow ${ }^{3}$

$$
\gamma_{\mathrm{S}}^{2}=-\left(\mathrm{p}_{1}-\mathrm{p}_{\mathrm{v}}\right) \int_{0}^{\mathrm{R}_{\infty}} \mathrm{r}^{2} \frac{\mathrm{dp}_{\mathrm{N}}(\mathrm{r})}{\mathrm{dr}} \mathrm{dr}
$$

where $R_{\infty}$ is a $r$ value of any point in the interior of the vapour and $\mathrm{p}_{\mathrm{N}}(\mathrm{r})$ is the normal pressure

$$
\mathrm{p}_{\mathrm{N}}(\mathrm{r})=\mathrm{p}_{\mathrm{K}}(\mathrm{r})+\mathrm{p}_{\mathrm{U}}(\mathrm{r})
$$

where $p_{U}(r)$ is configurational normal pressure and $p_{K}(r)$ is kinetic pressure

$$
\mathrm{p}_{\mathrm{K}}(\mathrm{r})=\mathrm{k}_{\mathrm{B}} \mathrm{T} \rho(\mathrm{r})
$$

with $k_{B}$ and $\rho(r)$ being Boltzmann constant and the density of the number of molecules, respectively ${ }^{8}$.

If we have $\gamma_{\mathrm{s}}$, then the relation ${ }^{6}$

$$
\frac{\gamma_{\mathrm{e}}}{\gamma_{\mathrm{S}}}=1+\left(\frac{\mathrm{R}_{\mathrm{e}}-\mathrm{R}_{\mathrm{S}}}{\mathrm{R}_{\mathrm{e}}}\right)^{2} \frac{\left(\mathrm{R}_{\mathrm{S}}+2 \mathrm{R}_{\mathrm{e}}\right)}{3 \mathrm{R}_{\mathrm{S}}}
$$

gives the surface tension $\gamma_{\mathrm{e}}$ corresponding to the equimolar surface.

Computer simulations study: Nanoscale liquid threads formed by argon atoms are our subjects investigated. Serving 
as an illustration of our scheme described above, we take 4800 particles to carry out this scheme for restrictive conditions $R_{e}$ $=\mathrm{R}_{\mathrm{e}}(\mathrm{T})$. form $^{9}$

The Lennard-Jones potential between particles takes the

$$
U\left(r_{i j}\right)=4 \varepsilon\left\{\left(\frac{\sigma}{r_{i j}}\right)^{12}-\left(\frac{\sigma}{r_{i j}}\right)^{6}\right\}
$$

where $r_{i j}$, e and $s$ are the inter-particle distance, energy scale and atomic diameter, respectively. For interatomic interaction, the parameters are chosen as $\mathrm{e} / \mathrm{k}_{\mathrm{B}}=93.16 \mathrm{~K}, \mathrm{k}_{\mathrm{B}}=1.38 \times 10^{-23}$ $\mathrm{J} / \mathrm{K}, \mathrm{s}=0.3405 \mathrm{~nm}, \mathrm{~m}=6.63382 \times 10^{-26} \mathrm{Kg}$. All quantities are reduced by reduced by $\varepsilon, \sigma$, Boltzmann's constant $\mathrm{k}$ and the particle mass $\mathrm{m}$. The rectangular box size of simulation system is $x^{*} \times y^{*} \times z^{*}=60.0 \times 60.0 \times 18.0$. The cutoff distance $r_{c}{ }^{*}$ is 3.0. The initial configuration was constructed by putting particles on a finite cubic lattice located at the central part of the box. The mirror boundary condition is used in X-direction and Y-direction. The periodic boundary condition is used in $\mathrm{Z}$-direction. The axis of symmetry of cylinder is Z-axis. At the initial time the particles were given velocities according to the Maxwell-Boltzmann distribution. The Velocity-Verlet algorithm is used in molecular dynamic simulation. The cell index method is adopted in calculation of force acted on atoms. The system is first thermalized during 130000 time steps and NVT ensemble is used before equilibration. The subsequent time long runs (up to 1000000 time step after an equilibration period of 130000 steps) are needed to obtain acceptable statistics. NVE ensemble will be needed to give the statistics of different parameters. Simulations are run at different temperatures: $\mathrm{T}=66,68,70,72,74,76,78,80$.

The values of $R_{\mathrm{e} 0}=R_{\mathrm{e}}\left(\mathrm{T}_{0}\right)$ and $\gamma_{\mathrm{e} 0}=\gamma_{\mathrm{e}}\left(\mathrm{T}_{0}, \mathrm{R}_{\mathrm{e} 0}\right)$ were calculated by molecular dynamics simulation. In this paper our aim of the stimulation is only to give a simple example for our method, therefore to avoid the expensive costs of computational time for adjustment of the particle number of the system according to a given function $\mathrm{R}_{\mathrm{e}}(\mathrm{T})$, we changed the temperature $\mathrm{T}$ and kept the total number of particles of the system including liquid and vapour $\mathrm{N}$ unchanged, so that the equimolar radius $\mathrm{R}_{\mathrm{e}}$ changed with the temperature spontaneously. Thus we easily obtained a numerical function $R_{e}(T)$ given by molecular dynamics simulation. In fact, we heated the system gradually from $66-80 \mathrm{~K}$ with interval $2 \mathrm{~K}$.

The numerical function $\Delta \mathrm{p}(\mathrm{T})$ were calculated for every $2 \mathrm{~K}$ by eqns. 18, (19) and molecular dynamics simulation.

The numerical function $\varepsilon_{\mathrm{e}}(\mathrm{T})$ were calculated by eqns. 15, 16, 21 and molecular dynamics simulation.

The numerical function $\gamma_{\mathrm{e}}(\mathrm{T})=\gamma\left(\mathrm{T}, \mathrm{R}_{\mathrm{e}}(\mathrm{T})\right)$ were calculated by eqn. 14 with use of $\mathrm{R}_{\mathrm{e} 0}$ and $\gamma_{\mathrm{e} 0}$.

\section{RESULTS AND DISCUSSION}

For the system of 4800 particles in a rectangular box with size $60.0 \sigma \times 60.0 \sigma \times 18.0 \sigma$, Fig. 1 gives a snapshot of simulated system after equilibrium

We give an example of radial density profile for a liquid thread with particles number 4800 in Fig. 2 . The density profile was calculated in the usual way by counting the number of molecules $\mathrm{N}(\mathrm{r})$ in the cylindrical shell with thickness $\Delta_{\mathrm{r}}=$

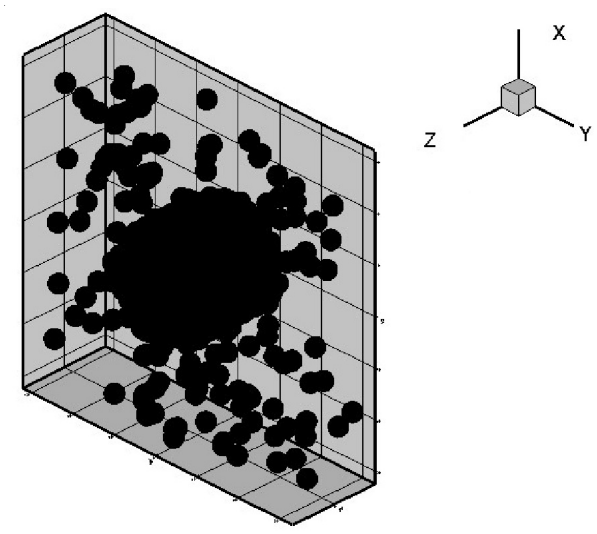

Fig. 1. A snapshot of simulated system after equilibrium

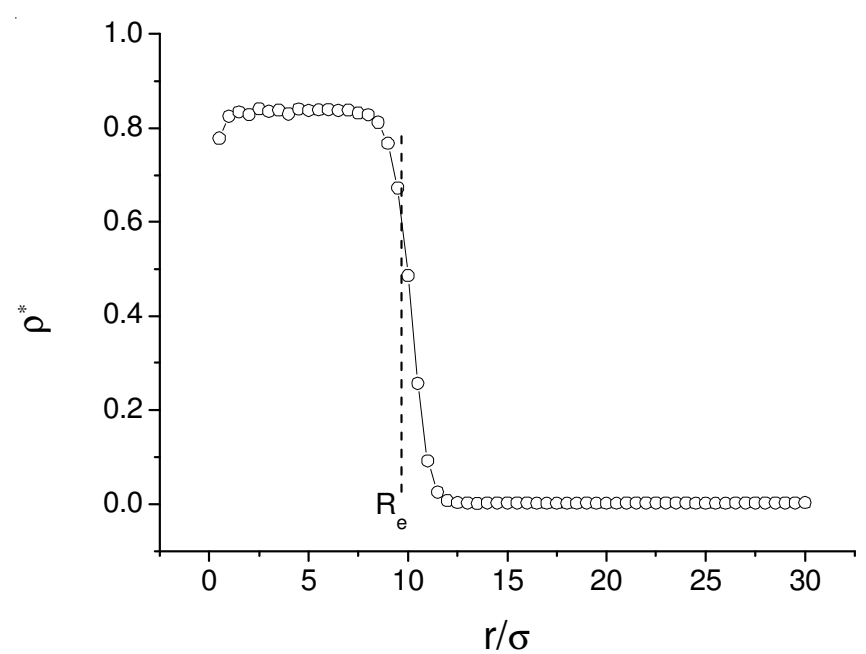

Fig. 2. Radial density profile at $\mathrm{T}=66 \mathrm{~K}$ for a liquid thread with particles number 4800

0.5 . The fluctuation of $\rho^{*}$ is related to the statistics. When the density profile was obtained, the radius of the equimolar surface can be determined.

The results of numerical functions $\mathrm{R}_{\mathrm{e}}{ }^{*}(\mathrm{~T}), \Delta \mathrm{p}^{*}(\mathrm{~T}), \varepsilon_{\mathrm{e}}{ }^{*}(\mathrm{~T})$ and $\gamma_{\mathrm{e}}{ }^{*}(\mathrm{~T})$ for $\mathrm{N}=4800$ are shown in Table-1. From Table-1, we know that the $\mathrm{R}_{\mathrm{e}}{ }^{*}$ decreases with increasing temperature, which is caused by evaporation. There is an overall decrease in the magnitude of the surface tension with increasing temperature, which is in good qualitative agreement with the predictions of thermodynamical theories ${ }^{8}$. More exactly, $\gamma_{e}{ }^{*}$ decreasing with increasing temperature attributes not only to the temperature change itself but also to the decrease of, which is called "Tolman effect" both of Tolman effect and temperature effect.

TABLE 1

MOLECULAR DYNAMICS SIMULATION RESULTS OF SURFACE TENSION AND RELATED INTERMEDIATE RESULTS

\begin{tabular}{cccccc}
\hline $\mathrm{T}$ & $\mathrm{T}^{*}$ & $\mathrm{R}_{\mathrm{e}}{ }^{*}$ & $\Delta \mathrm{p}^{*}$ & $\varepsilon_{\mathrm{e}}{ }^{*}$ & $\gamma_{\mathrm{e}}{ }^{*}$ \\
\hline 66 & 0.7085 & 9.839 & 0.062 & -0.015 & 0.582 \\
68 & 0.7300 & 9.827 & 0.058 & 0.006 & 0.559 \\
70 & 0.7514 & 9.806 & 0.055 & 0.020 & 0.535 \\
72 & 0.7729 & 9.782 & 0.053 & 0.038 & 0.520 \\
74 & 0.7943 & 9.755 & 0.049 & 0.059 & 0.487 \\
76 & 0.8158 & 9.733 & 0.046 & 0.084 & 0.463 \\
78 & 0.8373 & 9.691 & 0.043 & 0.111 & 0.422 \\
80 & 0.8587 & 9.656 & 0.042 & 0.125 & 0.416 \\
\hline
\end{tabular}




\section{Conclusion}

For the determination of surface tension of liquid threads from molecular dynamics simulations, the most time-consuming part, i.e., the part most difficult to enhance the precisionis the calculation of pressure tensors in the surface layer. To overcome this difficulty, we have deduced a formula that permits us to calculate the surface tensions by molecular dynamics simulation. The advantage of this method consists in decreasing the calculation quantity of pressure tensors in transition layer to the least. 4800 particles are taken to show how to carry out our scheme.

\section{ACKNOWLEDGEMENTS}

This work was supported by the Research and Development Program of Science and Technology of Higher Education of Shanxi Province (Grant No. 20121029).

\section{REFERENCES}

1. A.M. Gañán-Calvo, M. Pérez-Saborid, J.M. López-Herrera and J.M. Gordillo, Eur. Phys. J. B, 39, 131 (2004).

2. C.L. Yeh, Int. J. Heat Mass Transf., 52, 2026 (2009).

3. B.G. Kim, J.S. Lee, M. Han and S. Park, Nanosc. Microsc. Therm. Eng., 10, 283 (2006).

4. J.H. Irving and J.G. Kirkwood, J. Chem. Phys., 18, 17 (1950).

5. J.J. Magda, M. Tirrell and H.T. Davis, J. Chem. Phys., 83, 1888 (1985).

6. J.S. Rowlinson and B. Widom, Molecular Theory of Capillary, Clarendon Press, Oxford (1982).

7. M.J.P. Nijmeijer, C. Bruin, A.B. van Woerkom, A.F. Bakker and J.M.J. van Leeuwen, J. Chem. Phys., 96, 565 (1992).

8. S.M. Thompson, K.E. Gubbins, J.P.R.B. Walton, R.A.R. Chantry and J.S. Rowlinson, J. Chem. Phys., 81, 530 (1984).

9. M.P. Allen and D.J. Tildesley, Computer Simulations of Liquids, Clarendon Press, Oxford (1992)

10. R.C. Tolman, J. Chem. Phys., 17, 333 (1949). 